Portland State University

PDXScholar

1989

\title{
Maternal linguistic input to normal and expressive language delayed toddlers
}

Terril Joy Elwood

Portland State University

Follow this and additional works at: https://pdxscholar.library.pdx.edu/open_access_etds

Part of the Linguistics Commons, and the Speech Pathology and Audiology Commons Let us know how access to this document benefits you.

\section{Recommended Citation}

Elwood, Terril Joy, "Maternal linguistic input to normal and expressive language delayed toddlers" (1989). Dissertations and Theses. Paper 3864.

https://doi.org/10.15760/etd.5748

This Thesis is brought to you for free and open access. It has been accepted for inclusion in Dissertations and Theses by an authorized administrator of PDXScholar. Please contact us if we can make this document more accessible: pdxscholar@pdx.edu. 
AN ABSTRACT OF THE THESIS OF Terril Joy Elwood for the Master of Science in Speech Communication with an emphasis in Speech-language Pathology presented June 7, 1989.

Title: Maternal Linguistic Input to Normal and Expressive Language Delayed Toddlers.

APPROVED BY MEMBERS OF THE THESIS COMMITTEE:

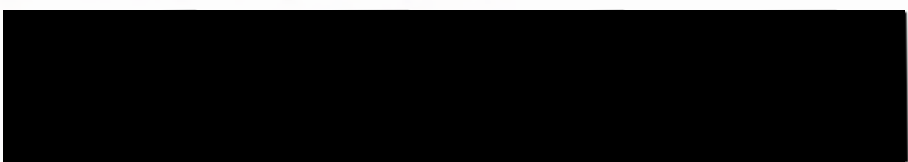

Rhea Paul, Chairperson

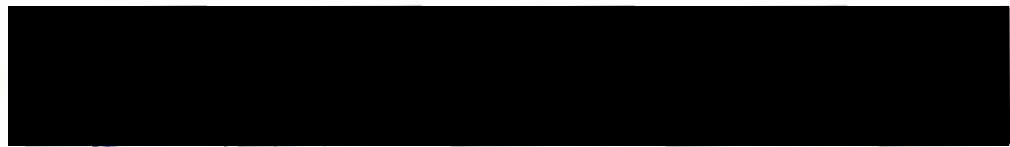

Joan MeMahon

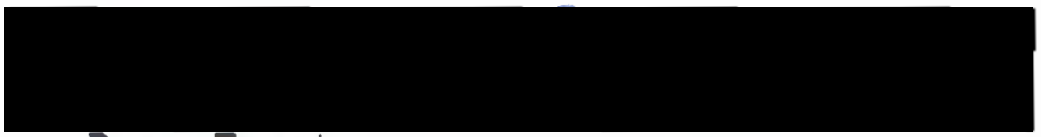

Dean Frost

Research suggests that the linguistic environment of the expressive language delayed child is different from that of his peers. Does this difference actually exist and if so, what are its characteristics? The purpose of this study was to describe the linguistic characteristics of mothers' input to children with normal language acquisition and those of mothers of expressively delayed toddlers; and to identify any differences between these groups. Though considerable research exists in this area, few studies have dealt 
specifically with large groups of expressively delayed toddlers.

Fifty-six mothers were instructed to play with their children as they would at home using a basket filled with age appropriate toys. Each ten minute interaction was videotaped and transcribed. Each transcription was analyzed and a percentage of occurrence calculated for the following measures: syntax, pragmatic function, lexical contingency and topic management.

Results of the Student's t-test indicated that the linguistic input of mothers of expressive language delayed toddlers was similar to that of the control group on most measures. Two areas emerged as different. Mothers of the normally developing toddlers tended to make more frequent use of expansion and extension. Also the MLU difference was found to be greater with the experimental group, though the maternal MLU of the two groups was not significantly different. 
MATERNAL LINGUISTIC INPUT TO

NORMAL AND EXPRESSIVE LANGUAGE DELAYED

TODDLERS

by

TERRIL JOY ELWOOD

A thesis submitted in partial fulfillment of the requirements for the degree of

\author{
MASTER OF SCIENCE \\ in \\ SPEECH COMMUNICATION
}

Portland State University

1989 
TO THE OFFICE OF GRADUATE STUDIES:

The members of the Committee approve the thesis of Terril Joy Elwood presented on June 7, 1989.

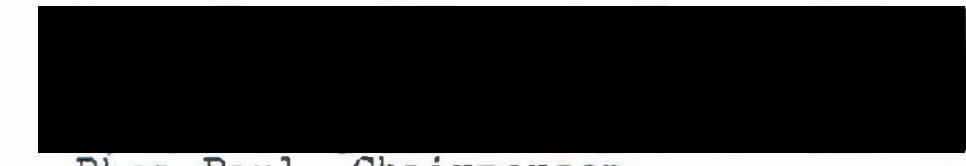

Rhea Paul, Chairperson

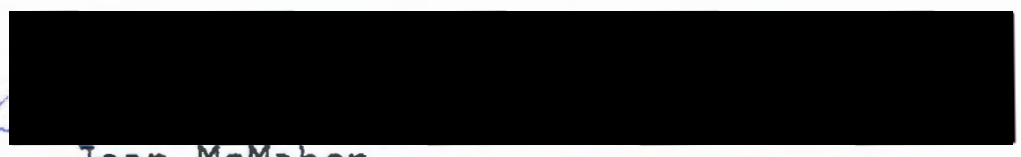

Joan MeMahon

Dean Frost

APPROVED:

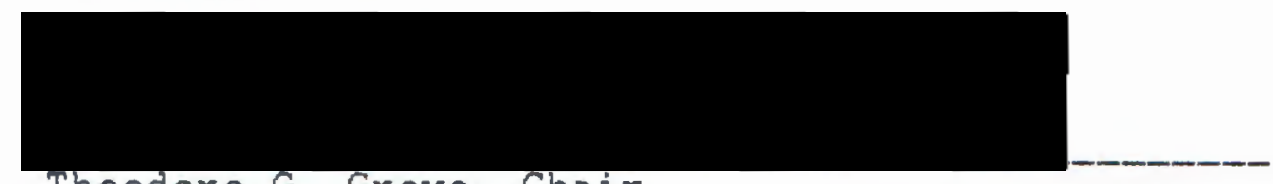

Theodore G. Grove, Chair

Department of Speech Communication

C. William Savery, Interion Vice Provost for

Graduate Studies and Regerch 


\section{ACKNOWLEDGEMENTS}

I want to thank everyone who helped me during the writing of this thesis. First of all, I wish to thank Dr. Rhea Paul for her guidance and encouragement. I want to thank her for the invaluable opportunity of participating in her language study on toddlers. Without her, this thesis would not be in existence.

I also wish to thank Joan MeMahon. She has provided good advice and support when I was overcome by the enormity of the task.

And to Sue Pinkerton and Laurie Schissler who put in long hours working on reliability, a heart-felt thank you. To Rita Bauersmith, Dana Hamburg and Pam Dahm, thanks for the hours you spent transcribing the tapes.

And finally, sincere thanks to my husband Bruce, who has lived with my thesis for the past year. 
TABLE OF CONTENTS

PAGE

ACKNOWLEDGEMENTS .

IIST OF TABLES.

CHAPTER

I INTRODUCTION AND STATEMENT OF PURPOSE . . 1

Introduction . . . . . . . . 1

Rationale and Statement of Purpose. 3

Definition of Terms . . . . . . 4

II REVIEW OF THE IITERATURE . . . . . . . . : 6

Character of Input to Preschoolers . 6

Character of Linguistic Input to

Language Delayed Children . . . . 12

Research Problems. . . . . . 18

Rationale for the Present Study . . 20

Parameters to be Measured . . . . 23

Predicted Results. . . . . . . 26

III METHODS . . . . . . . . . . . . . . 27

Subjects . . . . . . . . . . . 27

Procedures . . . . . . . . . 29 
CHAPTER

PAGE

IV RESULTS AND DISCUSSION . . . . . . . . 33

Results . . . . . . . . . . 33

Discussion . . . . . . . . . 38

$\checkmark$ SUMMARY AND IMPLICATIONS . . . . . . . . 43

Summary . . . . . . . . . . 43

Implications . . . . . . . . 45

SELECTED BIBLIOGRAPHY . . . . . . . . . . 48

APPENDICES

A DESCRIPTION OF MATERNAL PARAMETERS . . . 53

B HUMAN SUBJECTS RESEARCH REVIEW COMMITTEE APPROVAL . . . . . . . . . . . . 60

C QUESTIONNAIRE FOR PARENTS OF CHIIDREN 15-30 MONTHS OLD . . . . . . . . . 62

D INFORMED CONSENT . . . . . . . . . . 64

E VOCABULARY CHECKLIST . . . . . . . . . 66

F DEMOGRAPHIC DATA . . . . . . . . . . 58

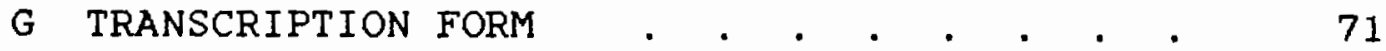

H SCORING FORMS . . . . . . . . . . 73 


\section{LIST OF TABLES}

TABLE

PAGE

I Subject Profile

II Syntax: Means and Standard Deviations. . . . . 34

II Lexical Contingency: Means and Standard Deviations. . . . . 35

IV Topic Management: Means and Standard Deviations . . . . . 36

V Pragmatic Function: Means and Standard Deviations 


\section{CHAPTER I}

\section{INTRODUCTION AND STATEMENT OF PURPOSE}

\section{INTRODUCTION}

The existence of a unique set of speech modifications termed Motherese (Olsen-Fulero, 1982) is well documented in the research literature (Gleitman, Newport \& Gleitman, 1984; Furrow, Nelson \& Benedict, 1979; Tiegerman, 1984; ContiRamsden, 1985). Mothers use Motherese when they are talking to young children, usually in their first two years of life (Owens, 1984). These speech behaviors are rather welldefined and include a wide variety of systematic behaviors in the areas of phonology, syntax, semantics, and pragmatics .

Mothers make predictable and measurable changes in their verbal interactions with their children but the role of these systematic changes is not clear. Anisfeld (1984) and others (Furrow, Nelson \& Benedict, 1979) suggest that Motherese is used to facilitate their child's acquisition of syntax. Newport, Gleitman and Gleitman (1977) suggest that the characteristics of a mother's language are determined by her underlying intent. In some cases, they feel the maternal intention is to control the child. Snow (1977) 
proposes, on the other hand, that some mothers may make linguistic adjustments designed to maintain a conversation with the child.

Research literature suggests that the linguistic environment of the language delayed child may be different from that of the normally developing child (Cramblit \& Siegel, 1977). Tiegerman (1984) suggests that mothers of language delayed children may actually maintain a language delay by providing the child with restricted linguistic input. Clezy (1979), in fact, assumes a need for the involvement of mothers in language intervention and the additional need for them to receive remediation as well as the child.

Yet some contradictory evidence is present in the literature. Lieven (1984) and Hoff-Ginsberg (1985) suggest that the issue is not the difference in linguistic input, but what the child is able to extract from that input. They contend that a wide variety of environments can provide the necessary components for language development. The difference then would lie in the abilities of the individual children, normal and expressively language delayed, to use available input to learn language. 


\section{RATIONALE AND STATEMENT OF PURPOSE}

\section{Raㅡ트므므르르}

The literature indicates that toddlers receive a linguistic input that is characteristically different from that which adults provide for each other and older children. There are also indications of further differences in the linguistic environment of the language delayed child. Little research deals directly with the large groups of expressive language delayed toddlers, thus no conclusions can be drawn regarding the linguistic environment of the language delayed child in this age group. Additionally, existing studies have produced contradictory results.

\section{Statement of}

The present study is designed to describe the linguistic characteristics of mothers' input to children with normal language acquisition and those of mothers of expressively delayed toddlers; and to identify any differences between these groups. Though considerable research exists in this area, few studies have dealt specifically with large groups of toddlers with an expressive language delay. Since the systematic modifications of Motherese occur particularly with toddlers, this study will compare the speech of the mothers of both expressive language delayed (ELD) and normal children in the 2.0-3.0 year range. The following question will be 
answered:

Is there a difference between the linguistic input that ELD children receive from their mothers and that which normally developing children receive?

However, it is not the intent of this study to determine or to even assume that a causal relationship exists between mothers' linguistic input and their child's expressive language acquisition since it is most likely that an interactional, dynamic relationship exists.

\section{DEFINITION OF TERMS}

1) Motherese: is a set of characteristic differences in speech directed to toddlers (Chapman, 1981). Changes are made in phonology, syntax, semantics and pragmatics .

2) Expressive Language Delay (ELD): will be used to refer to those children whose expressive vocabulary was less than or equal to ten words at $19-23$ months or less than 50 words or no two word combinations by 24 months (Paul \& Shiffer, 1987).

3) Lexical Contingency: will refer to the relatedness of maternal utterances to what the child is doing or saying. This will include imitation, extension and expansion (Moellman-Landa \& Olswang, 1984) and reference to child's activity. 
4) Pragmatic Function: refers to the intent or purpose of the utterance (Folger \& Chapman, 1978; Dore, 1977; Wanska \& Bedrosian, 1986). This includes requests for information, comments, requests for action, conversational devices, bids for attention and responses to the child's bids for attention.

5) Syntax: will refer to sentence organization. This will include declaratives, negatives, questions, imperatives, complex sentences, fragments and Mean Length of Utterance (MLU).

6) Topic Management: refers to which conversational partner, the mother or the child, initiates and maintains the topic (Wanska \& Bedrosian, 1985). 


\section{CHAPTER II}

\section{REVIEW OF THE LITERATURE}

Two basic questions exist in the literature regarding the Expressive Language Delayed (ELD) child and his/her linguistic environment. First, what is the character of the linguistic input to the young child? Is it a "Finely Tuned" (Retherford, Schwartz \& Chapman, 1981) input, designed to meet the needs of the developing child, as with normally developing toddlers; or is it somewhat static, requiring the child to select needed material from the input? Second, is the verbal environment of the language delayed child characteristically different from that of the child with normally developing language?

\section{CHARACTER OF INPUT TO PRESCHOOLERS}

The first question that the literature deals with concerns the character of the linguistic input provided for young children.

\section{Motheresese}

Research shows a set of characteristic differences in speech directed to toddlers (Chapman, 1981). As previously stated, these changes occur in the realms of phonology, 
syntax, semantics and pragmatics.

Phonological changes. Phonological changes in mothers' speech to toddlers include: 1) actual sound substitutions, and 2) prosodic changes including greater variability in pitch, intensity, duration and stress, with a slower speech rate and extensive use of pauses (Chapman, 1981).

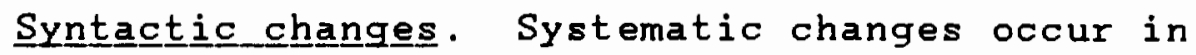
mothers' syntax as well. Her utterances tend to be more simple, avoiding complex constructions; and the actual length of the utterances are shorter than those used in speech to other adults. Research indicates that a mother's MLU may be directly related to the child's MLU (Chapman, 1981; Garnica, 1977; Cross, 1977). Cross (1977) suggests that when the child is $12-36$ months old, the maternal MLU is approximately 2-3 morphemes longer than the child's.

Syntactic adjustments also occur in mothers' choice of sentence type. Approximately one-third of her sentences are questions, one-third are declaratives, and one-third are imperatives (Newport, Gleitman \& Gleitman, 1977; Cross, 1977; Chapman, 1981). Chapman (1981) states that during the 2-3 year period, maternal speech begins to include "an equal number of Wh and $Y / N$ questions" ( $P$. 209).

Mothers also talk to their toddlers with fewer dysfluencies. Newport et al. (1977) report fewer than .1\% dysfluencies in maternal speech to 12-27 month-olds.

Semantic changes. Maternal vocabulary to toddlers is 
characterized by an unusual amount of redundancy. This redundancy is displayed in the use of imitation, expansion, and extension; utterances which are semantically related to the child's previous utterances. The content of the maternal utterances are usually concrete, relating to the on-going experiences of the child (Anisfeld, 1984; MoellmanLanda \& Olswang, 1984; Hoff-Ginsberg, 1985).

Praggmatic changes. In conversation with their toddlers, mothers use requests for information most often. Statements (comments) and requests for action are used less frequently (Cross, 1977). Chapman (1981) states that requests for action (directives) are used more frequently with the toddler than with younger children.

The frequently used request for information often inquires about the child's "internal state" (Sachs \& Devin, 1976, P. 85) whereas with older children, they may request real information about the "external world" (Sachs \& Devin, 1976, P. 85) of the child.

The chosen content of the interaction is generally determined by the child and is based on the present. Mother input often relates to the "ongoing contextual occurrences" (Tiegerman \& Siperstein, 1984); that is, she explains, clarifies and comments on the child's experiences as they occur (Gleitman, et al., 1984; Cross, 1977). She also tends to use expansions, extensions and imitations in conversation with the child, effectively maintaining and adding relevant 
information to the topic chosen by the child (Anisfeld, 1984; Moellman-Landa \& Olswang, 1984; Hoff-Ginsberg, 1985), in a highly redundant manner. Thus within the interaction, the child has the opportunity to have an effect on the maternal behavior and that in itself is a learning experience for the young child (Tiegerman \& Siperstein, 1984; Anisfeld, 1984; Conti-Ramsden, 1985). Throughout the interchange the mother and her child take turns, providing the child with a very early conversational experience (Tiegerman \& Siperstein, 1984).

\section{Role of Motherese}

The role of Motherese in language acquisition is not certain. Some researchers feel that Motherese provides toddlers with linguistic models that are closely matched to the child's language skills (Yoder \& Kaiser, 1989). Smolak (1987) studying 8 normal children at 10,14 and 18 months, concludes that maternal speech is influenced by child behavior. Others feel that the maternal linguistic output does not represent a "finely tuned" model. Retherford, Schwartz and Chapman (observing 6 normal mother-child dyads in two sessions - ages 19 to 27 months and 24 to 29 months in their 1981 study) suggest that children change to become more like the mothers, citing this as evidence against the Fine Tuning Hypothesis. Tiegerman and Siperstein (1984) combine these views; suggesting that the linguistic input is 
shaped by the child; with the adult carefully attuned to the child's communication. Gleitman, Newport and Gleitman (1984) from their study of 15 normal children ranging in age from 12 to 27 months, suggest that mother input does not change significantly as the child matures, but that the child selectively uses available material at one stage and not at another. They state that the learner has the burden for aquiring language.

It is also possible that additional factors may influence the dyadic communication exchange. O'Brien and Nagle (1987) present some rather interesting results in their study with toddlers, suggesting that toy selection may influence the linguistic input which the child receives. Their research suggests that children playing with dolls may receive more linguistic input than children who play with toys other than dolls.

Smolak and Weinraub (in their 1983 study of "high and low language" toddlers aged 23 to 25 months) conclude that there may be various styles of maternal speech which may have differential importance for child language acquisition and development.

\section{Summar $\underline{y}$}

This literature indicates that mothers' speech to toddlers is characterized by systematic changes in phonology (sound substitutions and prosodic changes), and syntax 
(simpler and shorter with a distinct distribution of utterance types). Semantic changes are seen in a high amount of redundancy and a very concrete vocabulary based on the child's on-going experiences. Speech to toddlers is also pragmatically altered. Mothers will most frequently use requests for information regarding the child's internal state. Statements or comments, and requests for action (directives) are used less frequently. Conversational content is usually based on the on-going experiences of the child, with topics chosen by the child and maintained by the mother through the use of imitation, expansion and extension. Throughout the conversational exchanges, the mother and her child take turns, giving the toddler early experience with conversational rules.

The role of Motherese remains uncertain. Motherese may be a finely tuned model that is closely matched to the child's input, and thus provide linguistic examples slightly more complex than the child's own linguistic skills, encouraging the child's language acquisition. On the other hand, Motherese may simply be a simplified manner of talking, from which children extract the needed linguistic material. 
CHARACTER OF LINGUISTIC INPUT TO

LANGUAGE DELAYED CHILDREN

A brief overview of the literature reveals some thought provoking data regarding the linguistic environment of the ELD child. The bulk of the research literature suggests that the linguistic environment of the ELD child differs from that of the normal child in specific and measurable ways .

Differences in the Linguistic Envir

Bondurant, Romeo and Kretschmer (1983) studied 28 mother child pairs, and found that mothers of children with delayed expressive language, (ranging in age from 2 to 5 years) used shorter utterances, used more directives and a greater amount of rejection utterances (giving evidence of rejecting what the child said, for example, saying, No, that is not a bal1). They suggest though, that this difference could possibly be the result of an adjustment on the part of mothers to compensate for the expressive language delay experienced by their children.

McDonald and Pien (1982) found in their study of 11 normally developing children (ages 29 to 36 months) that some mothers did not frequently use behaviors that elicit participation by the child, but rather, as was mentioned earlier, use behaviors that control the child. They suggest that this may even run the risk of influencing the child's 
language development by being less conducive to the growth of linguistic skills.

In studying 7 language disordered children (27-45 months) and 10 normai children (12-39 months), Lasky and Klopp (1982) found that maternal MLU and interactional types ("expansion imitation, exact imitation, reduction imitation, question use, answers, acknowledgements and providing information" ( $p .7)$ ) were not related to the child's language. This is contrary to the relationship found in normal dyads. There the mothers showed a significant relationship in this area.

In a study conducted by Whitehurst, Fischel, Lonigan, Valdez-Menchaca, DeBaryshe and Caulfield (1988), 17 28-month old ELD children, 14 17-month old children matched for expressive level and 10 28-month old children were matched for receptive level. They found that the pragmatic language interactions of the ELD group were similar to that of the group matched for expressive ability and different from that of the group matched for age. They also found that maternal MLU did not differ across the three groups.

Davis, Stroud and Green (1988) studied 6 boys (average age of 25.5 months) diagnosed as having a "simple language delay" ( $p .255$ ). These children were compared to 10 children ( 8 boys and 2 girls, average age 15.2 months) who were not delayed in any way and were comparable in language ability to the experimental group. In a free play 
situation, these researchers found that mothers of children with language delay talked less and used more commands with their children.

In three studies conducted by Cunningham, Siegel, van der Spuy, Clark and Bow (1985), language delayed boys were compared to normal boys. All subjects were between the ages of 28 and 68 months. In one study using 27 normal subjects and 33 language delayed subjects, they found that mothers questioned LD boys less frequently during tasks but did not differ from other mothers in other measures of interaction. In the second study, using 11 normal and 11 ELD subjects, maternal linguistic input was found to be significantly less complex to the experimental group. Then in their final study with 47 language delayed boys, the discrepancy between the speech complexity of the LD mothers and their children was found to be greater as the language delay (expressive and comprehension) increased.

Schodorf and Edwards (1983) looked at 10 language disordered children ("judged to be language deficient", ages 35 to 65 months) and 10 normal children (ages 19 to 37 months). Having matched these children for MLU, they found that the LD child received linguistic input that was shorter and simpler with more directives. In addition, there were more fragments and fewer complete sentences; more imperatives and corrections; and fewer declaratives, expansion, models, and what they termed "ready-made" 
utterances. They also concluded that the LD mother did not attend to the child's semantic content.

Tiegerman and Siperstein, (1984) found in looking at children ranging in age from 3 to 5 years that only $20 \%$ of the maternal utterances of the language disordered dyads were semantically related to their children's preceding utterances, whereas in normal interactions this percentage was found to be closer to 68\% (Snow, 1977; Cross, 1977). Tiegerman and Siperstein (1984) found that the verbal input was "highly restricted" ( $p$. 53) with 70 - 75\% questions. Their suggestion was that children with a language delay receive a limited range of semantic information, differing significantly from the amount normal children receive. They found that $80 \%$ of the mother's utterances were not related semantically to the LD child's vocal, verbal or nonverbal intentions. Mothers, in these cases, tended to talk about yesterday and tomorrow and about objects or events not in the immediately shared experience. Tiegerman and Siperstein (1984) labeled many maternal messages to be "unpredictable, irrelevant and extraneous" ( $p$. 55). In their study, mothers of language delayed children introduced new topics (not allowing the child to affect her behavior) and thus did not share the communicative roles. This was different than what accurs in normal mother-child interactions. These researchers also found that the LD children were given linguistic input that was significantly more complex than 
their level of comprehension. Their data led them to suggest that the environment of the LD child, being restricted, may actually maintain a language disorder.

In studying 14 dyads of language impaired children (ages 42 to 64 months) and 14 dyads of normal children (ages 19 to 33 months), Conti-Ramsdem and Friel-Patti (1984), found that mothers of the language impaired children initiate more frequently than do mothers of normal children. Subjects in this study were matched for MLU.

Finally, Cramblit and Siegel (1977) analyzed the linguistic input received by a 55 month-old LD boy and his 54 month-old cousin, a girl who was acquiring language at a normal rate. The $L D$ child received a more fluent input that was characterized by a lower Type Token Ratio (referring to the use of novel words) and a smaller mean length of response. The sentences directed towards the LD child tended to be arranged in simpler patterns than those directed towards his cousin.

Similarities in the Linguistic Environment of the ELD Child

Despite the strong indications of an altered linguistic input to language delayed children, some researchers view all environments as providing essentially the same types of input to both LD and normal children; and contend that the difference lies with the child (Lieven, 1984; Hoff-Ginsberg, 1985). Hoff-Ginsberg used 22 normal children ages 24 and 36 
months. She concluded from her study that it is possible that a wide variety of linguistic environments provide the essentials of linguistic input. Additionally, she felt that the language acquisition device (LAD), proposed by Noam Chomsky (Owens, 1984) may be able to make use of a wide variety of input types. These findings must be viewed in conjunction with other studies since only normal subjects were used in the study. Lieven (1984) suggests that the LD child may not be able to acquire language from a variety of situations, something the normal child accomplishes with apparent ease.

\section{Suummary}

Generally, the existing literature suggests that some differences exist in the linguistic environment of children with expressive language problems. The lack of homogeneity in subject selection and method design precludes the formation of any conclusive statements.

Overall, the studies cited in this discussion suggest the following features may be characteristic of the linguistic input to language delayed toddlers:

1) shorter utterances

2) more directives, and imperatives

3) more corrections

4) more rejection utterances

5) more mother initiations of topic 
6) utterances more complex than the child's comprehension level

7) more questions

8) more utterance fragments (in contrast to one researcher who found a more fluent type of input)

9) fewer sematically related utterances

10) fewer declaratives

11) fewer expansions, models and imitations

\section{RESEARCH PROBLEMS}

Though the literature seems to embody a great weight of information confirming the difference in the linguistic environment of the language delayed child, (note that most studies do not deal exclusively with the toddler), there are five basic problems with the literature regarding this issue.

\section{Focus of Studies}

First, a close examination of the literature reveals that the studies have focused on different parts of the mother-child dyad. This is not valid, according to ContiRamsden (1985), since the mother child interaction seems to be more a result of a mutual rather than individual regulation of behaviors. Both contributors to the interaction must be included in any study regarding the dyadic interaction. 


\section{Subject Definition}

Second, the definitions for the LD groups has varied to the extent that confident comparison cannot be made of the studies which supposedly sample the same populations (ContiRamsden, 1985). Additionally, individual studies have not defined their LD group clearly enough to assure that the children within an experimental group are similar (Cross, 1984).

\section{Number of Subjects}

Third, some studies have used a very small number of subjects, as low as one child in each group (Cramblit \& Siegel, 1977; Cross, 1984). In order for any generalizations to be made, the subjects must consist of a larger number than those used in the past studies.

\section{Mattching of Subjects}

Fourth, a variety of methods have been used to select and match the control groups to the experimental groups. Some studies matched LD children to normal children of the same chronological age (Bondurant, Romeo \& Kretschmer, 1983). Other studies matched subjects on the basis of language level measured in MLU (mean length of utterance) or MLR (mean length of response) (Conti-Ramsden \& Friel-Patti, 1984; Schodorf \& Edwards, 1983); and yet others matched subjects by mental age (Conti-Ramsden, 1985). The majority of the studies used middle-class subjects, or matched 
subjects controlling for socio-economic status.

\section{Design_of Stutudy}

Finally, there are very few studies designed to follow the LD child over a period of time. Most studies are crosssectional in nature and therefore complicate their results since the individual differences in parental linguistic style are not considered (Cross, 1984). In cross-sectional studies differences that may be individual, may in fact be attributed to the group. This complicates the interpretation of the results obtained.

\section{RATIONALE FOR THE PRESENT STUDY}

From the literature it can be concluded that definite differences exist in the linguistic input which toddlers receive to that which older children and adults receive. Systematic changes in phonology, syntax, semantics and pragmatics characterize mothers' speech to toddlers. The literature also seems to support the existence of additional differences in the linguistic environment of the language delayed child.

Research suggests that the verbal input directed towards the ID child may be syntactically more simple (though more complex than the child's), shorter, and more directive with a greater amount of rejection utterances, corrections, and questions. Unlike the speech to normal 
toddlers, the LD child appears to receive fewer declaratives (comments), fewer expansions, models \& imitations. Maternal utterances also appear to be less related to the child's preceding utterance and less related to the here and now. Input to the ELD child also appears to be more dysfluent than that of their normal peers. Some research indicates that the linguistic input to ELD children has a higher percentage of unintelligible utterances than that provided for normal children (Cross, 1984). Little analysis has been completed on negative sentence types.

Thus, there probably is a difference in the linguistic environments of children but further research is needed which will overcome the problems presented (Conti-Ramsden, 1985; Cross, 1984). Thus the characteristics of the linguistic input of mothers of ELD toddlers remains uncertain.

The present study is designed to add to the body of literature relating to the ELD child's linguistic input; and to overcome some of the problems cited above.

\section{Dyadic Characteter}

The analyses of maternal conversational behaviors will not occur in isolation from the child's utterances. Consideration of each maternal utterance will be completed within the context of the child's utterances. This procedure recognizes the dyadic, dynamic nature of the 
mother-child interaction. It is also important to note that this study is part of an on-going longitudinal study; part of which has examined the child's intentions expressed in the interactions which this study will analyze (see Paul \& Shiffer, 1987).

Subject Definition

The ELD subjects within the study were very clearly defined as mild to moderately expressively language delayed. This refers to those children whose expressive vocabulary was less than or equal to ten words at 19-23 months and less than 50 words or no two word combinations by 24 months (Paul \& Shiffer, 1987).

\section{Number of Subjects}

To overcome the limitations presented by a small subject number, 28 mother-child pairs of ELD children and 28 pairs of normal children will be used in this study.

\section{Match hing of Subjects}

Subjects pairs were closely matched for chronological age, sex, and socioeconomic status. The age range of all the subjects within both the experimental and the control group was 19-33 months.

\section{Design of thée_Stud}

The present study, though cross-sectional in nature, is a part of an on-going longitudinal study. The longitudinal 
study is designed to follow the language acquisition of both normal and ELD children to their entrance into Kindergarten or 1st grade.

\section{PARAMETERS TO BE MEASURED}

The literature indicates that the differences in the linguistic environment of the LD child are found in the areas of syntax, semantics and pragmatics. Cross (1984) grouped these differences into three catagories termed: 1) discourse contingencies, 2) sentence types and functions, and 3) input parameters. She states that these are the exact catagories of "parental language generally associated with language development in studies of normal children" ( $p$. 5).

The parameters chosen for analyses in the present study fit into the catagories outlined by Cross (1984) and thus are linguistic characteristics normally correlated with characteristic language input in normal children $12-36$ months of age. Detailed descriptions of the catagories selected for the study are provided in Appendix A.

\section{Lexical Contingency}

Lexical contingency will be measured by imitation, expansion and extension. A score will also be given to maternal utterances which refer to the child's previous ongoing utterance or activity (non-verbal). Research 
indicates that children are more likely to imitate utterances which are in themselves imitations of their own utterances. The use of these techniques increase the likelihood of the child imitating the adult's utterance and thus is viewed as a "facilitative technique" utilized by mothers to aid the child's language acquisition (Scherer \& Olswang, 1984). Chapman (1981) shows that these techniques are very frequently used by mothers in conversation with their toddlers. Maternal use of imitation, expansion and extension will be scored. Utterances which refer to the child's on-going activity (non-verbal) will also be scored.

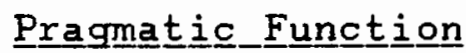

The pragmatic functions expressed by the mother will be measured by the underlying intent or purpose of the utterance. This catagory will analyze the speech functions which are directly related to the maternal choice of basic sentence types.

Research on the speech of mothers to their normal toddlers indicates that they most often use requests for information, then statements (or comments) and requests for action. Requests for information often ask about the "internal state" of the child (Sachs \& Devin, 1976, p. 85). Requests for action (directives) are used the least.

The literature also indicates that the topic of conversation is usually the child's choice with mother and 
child taking turns in the conversation. Thus the mother responds to the child's bids for attention and does not constantly bid for the child's attention.

\section{Syㅡㅡ르므}

Syntactic parameters will refer to sentence organization. Motherese is a syntactically simple register, related in length and complexity to the child's productions. Speech to toddlers is simple rather than complex with a lower percentage (as low as .1\%) of fragments. Cross (1977) found that mothers of normal toddlers used questions about one-third of the time, declaratives about one-third of the time, and imperatives $7 \%$ of the time. Chapman (1981) states that during the 2-3 year period the use of Wh and $Y / N$ questions is about equal.

\section{Topic Management}

Topic management refers to which conversational partner, the mother or the child, initiates and maintains the topic. Normally mothers in conversation with their children follow the topic lead of the child, allowing her to determine the choice of topic. Some studies suggest that mothers of ELD children tend to initiate topics more often than other mothers and do not follow the topic lead of the child. 
PREDICTED RESULTS

It is predicted that the results of this study will indicate that the linguistic environment of the expressive language delayed child is different. It is expected that those features of Motherese which have been found to correlate with language development in the normal toddler will appear less frequently in the linguistic input of the ELD child. 


\section{CHAPTER III}

\section{METHODS}

\section{SUBJECTS}

The subjects for this study were taken from a pool of mother-child pairs which were recruited for a longitudinal study at Portland State University. The subjects were recruited from local pediatric clinics and from newspaper ads. Approval was received from the Human Subjects Research Review Committee (Appendix B). The criteria for eligibility for the expressive language delayed group (ELD) was an expressive vocabulary of less than or equal to 10 recognizable words at $19-23$ months and less than 50 words or have no two word combinations by $24-34$ months. This information was obtained by parent report. Parent questionnaires were filled out by the child's parent and children meeting the criteria whose parents were interested, were contacted and invited to participate in the study. Parents were requested to provide information including parental occupation, the child's birth date, the number of different words the child used, and whether or not the child put words together to form short sentences (Appendix C). Parents were also asked to indicate their interest in being 
involved in the study. Children who did not meet the criteria and whose parents were interested were considered candidates for the control (normal) group. Each group consisted of 18 males and 10 females. The control group had an age range of 16 to 34 months and the experimental group had an age range of 19 to 33 months. All subjects passed a hearing screening at $25 \mathrm{dBHJ}$; all scored 80 or more on the Bayley Scales of Infeant Develelopment (Bayley, 1969). All mothers were interviewed with the Vineland Adaptive Behavion Scales (VABS ) (Sparrow, Balla \& Cicchetti, 1984). All the children who met the criteria for expressive language delay scored significantly lower on the $\underline{V A} \underline{B} \underline{S}$ expressive communication scale than their chronological age. All the normal children scored within the normal range for their age group.

Fifty-six mother-child pairs were selected from the pool of seventy-six dyads by Rhea Paul Ph.D. and assigned by her to the delayed or normal group based on the above criteria. This researcher remained blind to the group assignments until after the data was coded. On this basis, twenty-eight mothers of ELD children and twenty-eight mothers of children with normally developing language were included in the present study. The two groups were matched for age, sex, and socioeconomic status. Socio-economic status was calculated using Myers and Bean's (1968) adaptation of the Hollingshead Four Factory Index of Social 
Position. At the time of the first assessment, parents of all the subjects signed permission forms to participate in the study and completed a rocabulary checklist (Appendices $D$ and $E$ ).

\section{TABLE I}

SUBJECT PROFILE

Control Group
Experimental

Group

Sex

Males

Females

Chronological Age

Mean

SD

Range

Socio-economic Status

Mean

SD

Range
18

10

25.5

4.52

16-34

2.6

1.35

1-5
18

10

25.1

3. 92

19-33

2.8

.97

1-5

Refer to Appendix $F$ for a complete listing of the demographic data.

\section{PROCEDURES}

The subjects were seen in a clinic room at Portland State University. Each mother-child pair was given a standard set of toys (including dolls, Disney Poppin' Pals, a telephone, dishes, cars and a xylophone), and asked to play. The following instruction was given to each parent: "Please play with your child as you normally would at home. 
I will be videotaping you for ten minutes" (Paul \& Shiffer, 1987; Shiffer, 1988). All the subjects were seated on a carpeted area of the floor for the duration of the videotaping. The ten-minute video recordings of the motherchild interactions were transcribed using English orthography. All intelligible utterances were literally transcribed and notation was made of the content of other child intentions expressed nonverbally (either by gesture, vocalization or by a combination of the two). Only maternal utterances which were directed to the child were coded. Thus maternal utterances during make-believe telephone conversations to individuals other than the child, were not coded. The Transcription Form is displayed in Appendix G.

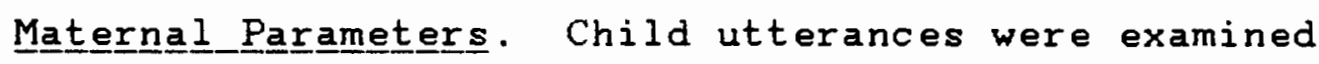
for content in order to judge the relatedness of the mother's speech. (Refer to Appendix A for a detailed description of the maternal parameters.) Mean Length of Utterance was calculated on both mother's and child's productions and the mean difference calculated within each group. The percentage of occurrence of the following maternal speech behaviors was tabulated on scoresheets:

1) Lexical contingency - imitation, expansion, extension and reference to child's activity

2) Pragmatic function - requests for information (internal state and external state, and clarification), comments (positive and negative), requests for action 
(directives) and soliciting attention.

3) Syntax - declaratives, negatives, questions (wh, $Y / N$, and tag), imperatives, fragments and complex sentences.

4) Topic management - introduction of topic, reintroduction of topic, response to child's topic choice and reintroduction of child's previously chosen topic.

Scoring. Scoring was done by analyzing each maternal utterance within the context of the child's utterances. Each utterance was examined for the presence of these features, and the utterance number written on the appropriate scoresheet, showing that sentence to be an exemplar of the language behavior. All exemplars of each structure was then tallied and a percentage of occurrence calculated relative to the mother's total number of utterances in the 10 minute sample. Scoring Forms are displayed in Appendix H.

Reliability. The researcher and three trained speech pathology students transcribed the tapes. A three minute segment of $6 \%$ of the tape transcriptions were reviewed by the examiner with an overall inter-rater reliability of $87.6 \%$.

The researcher calculated intra-rater reliability of the tape analysis by recoding the middle 30 utterances of $20 \%$ of the tapes. Reliability on the syntactic variables was $98 \%$, on the pragmatic variables $93 \%$, on lexical contingency $96 \%$ and on topic management $91 \%$. Inter-rater reliability was obtained using two speech pathology 
students, trained in the coding system by the researcher as raters. Reliability on the transcription analyses was calculated by independent recoding of the middle 30 utterances of $20 \%$ of the tapes. Reliability on the syntactic measures was $93 \%$; on pragmatic functions $78.9 \%$; on lexical contingency $90 \%$ and on topic management $90.9 \%$. Intra-rater reliability on MLU difference was also calculated, with a reliability of $99.2 \%$. Inter-rater reliability on this measure resulted in a reliability of 92\%. These figures suggest good reliability for the coding of maternal utterances.

Data Analysis. Percentage of occurrence of the remainder of the target behaviors was tabulated for each group. Measures of central tendency and variability were also obtained for each group. The data obtained regarding the MLU of mothers and children was summarized with measures of central tendency and variability for each group. Then the difference between the mean MLU of the mothers of each group and their children was calculated. A comparison was made between the control group (children with normal language acquisition) and the experimental group (expressive language-delayed children) using the Student's t-test. 
CHAPTER IV

RESULTS AND DISCUSSION

\section{RESULTS}

The means for both groups on all variables coded were examined. A two-tailed Student's t-test was calculated on the nine variables with the largest differences between group means. This method was used in order to complete the fewest number of $t$-tests possible, thus reducing the risk of Type I errors. In addition a .01 level of significance was used, again to minimize the risk of Type I errors in doing multiple t-tests. Only three of the nine variables with the greatest differences between means examined presented significant differences at alpha level .01. It is assumed that the areas not examined statistically showed insignificant differences, since mean differences for these variables were smaller than those tested for significance.

Syntax. Table II shows the means for both groups on the syntax measures. The difference between the MLU of mothers and their children was significantly greater in the expressively delayed group than in the normal group (alpha Ievel .01). No other significant differences were found. 
TABLE II

SYNTAX
MEANS AND STANDARD DEVIATIONS

$\begin{array}{cccc}\text { Control } & \text { Experimental } & t & p \\ \text { Group } & \text { Group } & \text { value } & \text { value }\end{array}$

Declaratives

$\begin{array}{lrr}\text { Mean } & 16.83 & 16.06 \\ \mathrm{SD} & 7.32 & 8.19\end{array}$

Negatives

$\begin{array}{lll}\text { Mean } & 4.38 & 3.81\end{array}$

$\begin{array}{lll}\mathrm{SD} & 3.65 & 2.83\end{array}$

Wh Questions

$\begin{array}{lrr}\text { Mean } & 12.68 & 11.26 \\ \mathrm{SD} & 5.42 & 5.68\end{array}$

Y/N Questions

Mean 12.85

13.13

SD

5.77

6.29

Tag Questions

Mean $\quad 1.70$

1.22

SD $\quad 1.77$

1.47

Complex Sentences

Mean 6.30

3.98

2.17

.01

$S D$

4.87

2.89

Imperatives

Mean $\quad 10.21$

SD $\quad 7.72$

10.89

6.31

Single Fragment

Mean

23.99

27.99

SD

11.70

8.17

Multi Fragment

Mean $\quad 10.60$

11.34

SD

4.21

5.13

Maternal MLU

Mean

SD

Child MLU

Mean

SD

Difference

Mean

SD
4.22

1.0

1.95

.78

2.23

.82
3.93

.64

*significant difference 
Lexical Contingency. Table III shows the means for both groups on the lexical contingency measures. The control group and the experimental group were found to differ significantly in the use of expansions. In addition, the difference in use of extensions approached significance, with the normals using the technique more frequently.

TABLE III

LEXICAL CONTINGENCY
MEANS AND STANDARD DEVIATIONS
$\begin{gathered}\text { Control Experimental } \\ \text { Group } \\ \text { Group }\end{gathered}$

Imitation

Mean

SD

4.74

1.97

3.04

2.69

.01

Expansion

Mean

4.50

4.19

1.12

3.40

2.28

3.97

$.01 *$

SD

Extension

Mean

2.36

3.24

.64

1.62

2.47

$.01+$

Ref. to Child's Activity

$\begin{array}{lll}\text { Mean } & 78.35 & 84.11 \\ \text { SD } & 13.35 & 10.75\end{array}$

$-1.46$

.01

*significant

tapproaches significance 
Iopic Management and Pragmatic Function. Tables IV and $V$ display the means for both groups on the topic management and pragmatic function measures. In these areas, the data failed to show significant differences in any of the paramenters examined. Thus, the two groups were found to be similar in the way mothers managed conversational topics, and in the types of pragmatic functions employed.

\section{TABLE IV}

TOPIC MANAGEMENT

MEANS AND STANDARD DEVIATIONS

$\begin{array}{cccc}\text { Control } & \text { Experimental } & t & p \\ \text { Group } & \text { Group } & \text { value } & \text { value }\end{array}$

Intro, of New Topic

Mean

SD
4.41

2.48
5.35

3. 34

Reintro. of Maternal

Topic

Mean

$S D$

1.16

1.46

1.53

1.85

Respond to Child's

Topic

Mean

SD

47.37

55.52

21.52

Reintro. of Child's

Topic

Mean

24.24

SD

1.03

.96

Maintain Maternal

Topic

Mean

$\mathrm{SD}$

37.82

23.49

28.81

19.54

.01

$-1.33$ 


\section{TABLE V}

PRAGMATIC FUNCTION

MEANS AND STANDARD DEVIATIONS

$\begin{array}{cccc}\text { Control } & \text { Experimental } & t & p \\ \text { Group } & \text { Group } & \text { value } & \text { value }\end{array}$

Request Information

Internal

$\begin{array}{lrr}\text { Mean } & 12.01 & 10.48 \\ \text { SD } & 6.38 & 5.60 \\ \text { Mication } & & \\ \text { Mean } & 5.71 & 3.53 \\ \text { SD } & 4.19 & 3.65\end{array}$

External

Mean

15.96

15.22

SD

6.90

6.55

Comments

Positive

Mean

SD

27.32

8.61

32.03

$-1.67 \quad .01$

Negative

Mean

2.12

12.14

SD

2.20

2.44

3.57

Request Action

Mean

19.66

SD

8.62

20.42

8.96

Conversational Devices
Mean
SD
11.42
7.23
10.47
6.55

Imitation
Mean
1.77
1.13
SD
1.89
2.25

Bids for Attention
Mean
2.78
2.87
SD
4.41
3.28

Responses to Child's Bid

for Attention

Mean

.84
1.95

SD 


\section{DISCUSSION}

The primary purpose of this study was to identify the existence of differences in the linguistic environment of the ELD toddler, specifically in the maternal input provided for the child. If such differences were found, implications would exist for parent training.

Overall, the results obtained in this study suggest that the two groups of mothers are similar in many aspects of linguistic input to their toddlers, though a few differences appear. These differences relate to language complexity and lexical contingency. The overall similarity between the two groups correlates with the results of the studies completed by Conti-Ramsden and Friel-Patti in 1983 and 1984. In this study, mothers of language impaired children were found to use essentially the same number of requests, comments and directives as mothers of normal children.

Syntax. This study found that though the data failed to show significant differences between the Maternal MLU of the two groups, the difference between the MLU of mothers and their children was significantly greater in the experimental group. This finding is of interest since the literature presents an ambiguous picture of the linguistic complexity of the ELD child's environment. This MLU difference could be explained in several ways. 
Some researchers have raised an interesting issue: to what are the mothers tuning their language? It may be that mothers are tuning to either the comprehension level or the expressive level of their child (Retherford, Schwartz\& Chapman, 1981). It is possible that the mothers in the ELD groups are tuning their linguistic input to the comprehension level of the child rather than the expressive level. This is supported by the greater difference between maternal and child MLU in the experimental group. Additionally, Spangle-Looney (1988) found that the ELD children had higher comprehension than production level. If they are pitched to their child's comprehension level, the linguistic input of the ELD mothers may be appropriate for the level of comprehension, while the larger difference between utterance lengths reflects the lower expressive level of the ELD children. This is an important consideration since the literature indicates that a child is most likely to understand and use "language form and content at or just above [his] level" (Peck, 1989, p. 5). Thus, the maternal MLU may be at an appropriate model for the ELD child.

Since the maternal MLU of the two groups is not significantly different, these data suggest that the maternal input received by the ELD group is neither more nor less complex than that of the normal group. The focal issue then concerns the relationship between comprehension level 
and expressive abilities. If comprehension level is higher than the expressive level, then it may be that maternal input is pitched at the optimum level.

Another possibility exists. Since the literature indicates that children are more likely to imitate utterances which are imitations of their own productions, it may be that though ELD mothers are correct in assuming high comprehension, their model is too demanding, or complex for their children to imitate (Folger \& Chapman, 1978). Barnes, Gutfreund, Satterly and Wells (1983, p. 75) suggest that "children need to receive input which is on the average neither too simple nor too complex." Mothers of ELD children may be providing linguistic models that are too advanced for their child's expressive level. If this interpretation is valid, parents of ELD children may need to be taught to produce simpler utterances which are more closely matched to the child's expressive level. The child may then imitate parental utterances more readily.

Cramblit and Siegel found in their 1977 study that the LD child received a less fluent type of input than the normally developing child. This was not found in the present study. Measures of utterance fragments were not found to be significantly different between the two groups. No other significant differences were found in this study.

Lexicical Contingency. The ELD mothers were found to 
refer to their child's activities as often as the control group. It appears from these data, that the EID mothers are basically doing a good job of providing their toddlers with appropriate input. The data supports the contention that they are equally likely to use their child's utterances and activities as sources for conversation topics, but is contrary to some literature which suggests that ELD mothers are less responsive to their children's language than mothers of normal children (Lasky \& Klopp, 1982).

As suggested in the literature (Schodorf \& Edwards, 1983), mothers of normal toddlers used more expansion. They were more likely than ELD mothers to take what the child said and expand it to a more adult like form, while preserving the original intent of the utterance.

These data also indicated that the control mothers made somewhat greater use of extension. This result approached significance, supporting the literature which indicates that mothers of normal children more frequently produce utterances which are semantically related to the child's utterance. One reason for this behavior may be that mothers of normal children simply have more child utterances upon which to expand and extend. The implications this finding has for parent training will be discussed in the next section.

The contention presented by Tiegerman and Siperstein (1984) suggesting that the ELD child's linguistic 
environment was restrictive and semantically related to the child's environment less often than that of the normal child, was not substantiated.

Topic_Managegement. No significant differences were found in this area. Contrary to the literature (Tiegerman \& Siperstein, 1984), which suggests that ELD mother are more likely to initiate conversational topics than to follow the child's lead, this study suggests that this is not the case. These data show that the mothers of both groups are equally likely to initiate topics of conversation.

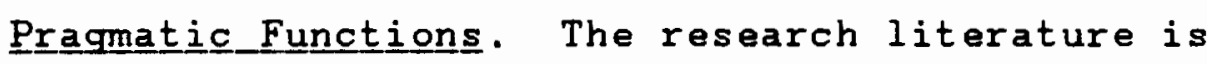
divided in this area. Some studies suggests that ELD mothers are more directive and use more requests for action (often expressed syntactically as imperatives). It also suggests that they use more rejections and corrections. Other researchers (Whitehurst, Fischel, Lonigan, ValdezMenchaca, DeBaryshe \& Caulfield, 1988) found no differences in the pragmatic interactions of normal and ELD dyads. The current findings support this suggestion. There was no difference found in any of the pragmatic functions (coded as requests for information, comments, requests for action, conversational devices, bids for attention and response to bids for attention), nor was there a difference in the syntactic form of imperatives. In fact, the two groups were found to be similiar in all aspects of Pragmatic Function . 


\section{CHAPTER V}

\section{SUMMARY AND IMPLICATIONS}

\section{SUMMARY}

Research into the linguistic environment of the Expressive Language Delayed (ELD) child is inconclusive. Methods vary from study to study, preventing replication of results. Some studies have matched children for chronological age (as in the present study), whereas others have matched the children for expressive language ability.

This study examined the linguistic input of mothers of twenty-eight normal children and twenty-eight mothers of children with an expressive language delay. These groups were matched for chronological age, sex, socio-economic status, passed a hearing screening at $25 \mathrm{dBHL}$ and scored at least 85 on the Bayley Scaales of Infant Development (Bayley, 1969) .

All mother-child dyads participated in a video-taped free play interaction. These interactions were transcribed and coded for syntactic, pragmatic, lexical and topic variables. The resultant data were analyzed for significant differences between the two groups. The results indicated that the two groups were similar on most of the measures 
examined in this study. Thus the results from the present study found that maternal linguistic input to ELD children was similar to that of mothers of normal children in the following measures :

1. mean length of utterance.

2. proportion of directives and imperatives.

3. proportion of corrections and rejections.

4. proportion of maternal initiations of topic.

5. sentence complexity.

6. proportion of questions.

7. proportion of fragments.

8. proportion of semantically related utterances.

9. proportion of declaratives.

10. proportion of utterances related to the child's activities.

11. proportion of imitations.

The control group was found to use significantly more expansion. They were also found to use more extension at rate that approached significance. Also, the difference between the maternal MLU and the child MLU was greater for the ELD group. No other differences were found.

It was concluded that the mothers of both groups were providing essentially the same input to their children with some possible exceptions in the area of teaching functions of language. 


\section{IMPLICATIONS}

\section{Research}

More research is needed to fully understand the relationship that exists between a child's expressive language delay and the maternal linguistic input provided. An exploration of the interaction between child's ability and mother's input based on both chronologically matched and language ability matched groups is needed. Existing studies have examined this relationship with few subjects. Additionally, future research will need to examine differences in maternal speech that may arise when subjects are placed in an unfamiliar situation, such as a clinic room. A closer examination of maternal speech must be made in both the unfamiliar clinic setting and in the familiar home setting. Also, it may be necessary to examine maternal speech that is produced when the mother does not feel she needs to "perform". It is possible that daily maternal speech may differ from samples obtained in a structured clinic setting.

Since mothers may be providing input based on their perception of their child's comprehension level, it would be of interest to assess the accuracy of these maternal perceptions. It could be that mothers base their input on a belief that their child's receptive abilities are greater than they are in actuality. 
If ELD children require a different type of language input for their linguistic growth, an examination of the components and effects of a parent training program would be of interest.

Since the mother-child dyad is truly a dynamic, interactional interchange, it would be interesting to examine maternal linguistic models when the children are even younger and still non-verbal. This might provide a scenario in which the child is more of a responder in the exchange and the mother in even more control.

\section{Clinical}

These data suggest that maternal linguistic models to ELD toddlers are similar to that provided for normally developing toddlers. A few differences exist in the use of expansion and extension, two techniques usually thought of as facilitative for language growth.

The results of this study may have some implications for the clinical setting. Mothers of ELD children may wonder what they are doing that is affecting their children. This study suggests that these mothers are providing input, with some exceptions, that is essentially the same as that of mothers of children with normal expressive language. These data indicate that the mothers of the ELD children may be using the teaching techniques of expansion and possibly extension, less often than the mothers of normal children. 
Since these techniques are thought to facilitate language acquisition, maternal training in these areas may be of benefit to the ELD child. One must bear in mind however, that the parent can only make use of these techniques if the child is verbal. If the child is nonverbal, the mother has nothing to extend or expand.

Additionally, it may be that the ELD child requires a different environment to exhibit the same type of growth as that of the normally developing child. Because of the MLU difference, there is some suggestion that the mothers of the ELD children may need to tune their input more closely to the expressive level of their children than they are at present. The case may be that these children need simplified linguistic input; but uniquely enriched in order to stimulate expressive language growth.

Finally, it is imperative that any parent training program must incorporate the presupposition that the mother of an ELD children is probably behaving much like a mother of a normally developing child. 


\section{SELECTED BIBLIOGRAPHY}

Anisfeld, M. (1984). Langua Three. Hillsdale, NJ: Lawrence Erlbaum Associates, Publishers.

Barnes, S., Gutfreund, M., Satterly, D. \& Wells, G. (1983). Characteristics of adult speech which predict children's language development. Journal 1 of Langua

Bayley, N. (1969). Bayley Scales of Infant Development. NY: Psychological Corporation.

Bondurant, J.L., Romeo, D.J. \& Kretschmer, R. (1983). Language Behaviors of Mothers of Children with Normal and Delayed Language. Languagae, Speech, and Hear Services in Schools, 14 , 233-242.

Chapman, R.S. (1981). Mother-child interaction in the second year of life: Its role in language development. In Schiefelbusch, R.L. \& Bricker, D.D, (Eds.), Early language: Aquisition and intervention. Maryland: University Park Press.

Clezy, G. (1979). Modificaltion of the mother-chil interch hange in languagge, speech and hearing. Baltimore, MD: University Park Press.

Conti-Ramsden, G. \& Friel-Patti, S. (1983). Mothers' discourse adjustments to language-impaired and nonlanguage-impaired children. Journal of Speech and

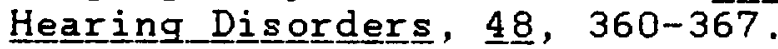

Conti-Ramsden, G. \& Friel-Patti, S. (1984). Mother-child dialogues: A comparison of normal and language impaired children. Journal of Communication Disorders, 17, 1935 .

Conti-Ramsden, G. (1985). Mothers in dialogue with language-

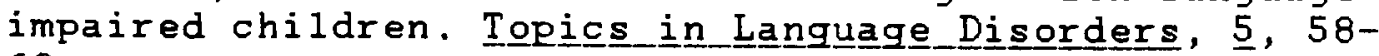
68.

Cramblit, N.S. \& Siegel, G.M. (1977). The verbal environment of a language-impaired child. Journal_of Speech and

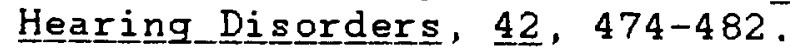


Cross, T. (1977). Mothers' speech adjustments: The contribution of selected listener variables. In C.E.

Snow and C.A. Ferguson (Eds.), Talking to children,

Cambridge, England: Cambridge University Press.

Cross, T. (1984). Habilitating the language-impaired Child: Ideas from structures of parent-child interaction. Topics in Language Disorders, $4,1-14$.

Cunningham, C.D., Siegel, L.S., van der Spuy, H.I.J., Clark, M.L.\& Bow, S.J. (1985). The behavioral and Iinguistic interactions of specifically language-delayed and normal boys with their mothers. Chhildㅁevelopment, $\underline{5} 6$, 1389-1403.

Davis, H., Stroud, A. \& Green, L. (1988). The maternal language environment of children with language delay. Britishㅡ Journal of Disorderers of Communicaticion, $23,253-$ 266 .

Dore, J. (1977). Children's illocutionary acts. In R. Freedle (Ed.), Discourse relations: Comprehension and production, (pp. 227-244). Hilisdale, NJ: Lawrence Erlbaum Associates.

Folger, J. \& Chapman, R. (1978). A pragmatic analysis of

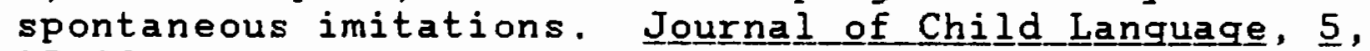
25-38.

Furrow, D., Nelson, K. \& Benedict, H. (1979). Mother's speech to children and syntactic development: Some simple relationships. Journal of Child Languagae, 6 , 423-442.

Garnica, O.K. (1977). Some prosodic and paralinguistic features. In C. Snow \& C. Ferguson (Eds.), Talking to children, Great Britain: University Press, Cambridge, (pp. 63-88).

Gleitman, L.R., Newport, E.L. \& Gleitman, H. (1984). The current status of the motherese hypothesis. Jouuㅡ므므음 Child﹎﹎ㅡㅡ므므를, $2,43-79$.

Hoff-Ginsberg, E. (1985). Some contributions of mothers' speech to their children's syntactic growth. Journal of Child Languagge, 12, 367-385.

Lasky, E.Z. \& Klopp, K. (1982). Parent-child interactions in normal and language-disordered children. Journnal of

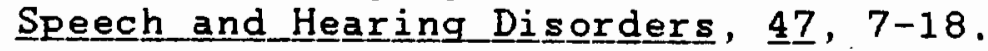


Lieven, E.V.M. (1984). Interaction style and children's language learning. Topics in Language Disorders, $\underline{4}$, 15-23.

Mcdonald, L. \& Pien, D. (1982). Mother conversational behavior as a function of interactional intent. Journal of Child Lanquage, $9,337-358$.

Miller, J.F. (1981). Assessing language production in children: Experimental procedures. Baltimore, MD: University Park Press.

Moellman-Landa, R. \& Olswang, L.B. (1984). Effects of adult communication behaviors on language-impaired children's verbal output. Applied Psycholinguistics, 5, 117-134.

Myers, J.K. \& Bean, L.L. (1968). A decade later: A followup of social clasㅗ을 and mental ilness. NY : Wiley \& Sons.

Newport, E., Gleitman, H. \& Gleitman, L. (1977). Mother, I'd rather do it myself: Some effects and non-effects of maternal speech style. In C.E. Snow \& C.A. Ferguson (Eds.), Talking to Children: Language input and acquisition. Cambridge, England: Cambridge University Press.

O'Brien, M. \& Nagle, K. (1987). Parents' speech to toddlers: the effect of play contexts. Journal of Child Languuage, 14, 269-279.

Olsen-Fulero, L. (1982). Style and stability in mother conversational behaviour: A study of individual differences. Journal of Child Language, 9 , 543-564.

Olson, S.L., Bayles, K. \& Bates, J.E. (1986). Mother-child interaction and children's speech progress: A longitudinal study of the first two years. Merrill= Palmer Quarterly, 32, 1-20.

Owens, R.E. (1984). Language development: An introduction. Columbus, OH: Charles E. Merrill Publishing Company.

Paul, R. \& Shiffer, M. (1987, November). An examinationon_of communication intentions in speech-delayed toddlers. Paper presented at the ASHA National Convention, New Orleans, LA.

Peck, C.A. (1989). Assessment of social communicative competence: Evaluating environments. Seminars in Speech and Language, 10, 1-15. 
Retherford, K.S., Schwartz, B.C.\& Chapman, R.S. (1981). Semantic roles and residual grammatical categories in mother and child speech: Who tunes into whom? Journal of Child Language, $\underline{8}$, 583-608.

Sachs, J. \& Devin, J. (1976). Young children's use of age appropriate speech styles in social interaction and role-playing. Journal of Child Language, 3 , 81-98.

Scherer, N. \& Olswang, L. (1984) Role of mother's expansions in stimulating children's language production. Journal of Speech and Hearing Research, 27, 387-396.

Schodorf, J.K. \& Edwards, H.T. (1983). Comparative analysis of parent-child interactions with language-disordered and linguistically normal children. Journal of Communication Disorders, $16,71-83$.

Shiffer, M.E. (1988). A comparison of communication intentions in toddlers between sixteen and thirty-four months of age. Unpublished master's thesis, Portland State University, Portland, Oregon.

Smolak, L. (1987). Child characteristics and maternal speech. Journal of Child Language, 14, 481-492.

Smolak, L. \& Weinraub, M. (1983). Maternal speech: strategy or response? Journa I of Chi IId Lanquage, 10, 369-380.

Snow, C.E. (1977). Mother's speech research: From input to interaction. In C.E. Snow and C.A. Ferguson (Eds.), Talking to Children: Language Input and Acguisition, (31-49). Cambridge, England: Cambridge University Press.

Spangle-Looney, S. (1988). Communication and socialization profiles in toddlers with expressive language delay. Unpublished master's thesis, Portland State University, Portland, Oregon.

Sparrow, S.S., Balla, D.A. \& Cicchetti, D.V. (1984). Vineland Adaptive Behavior Scales - Survey Form. Circle Pines, MN: American Guidance Service, Inc.

Tiegerman, E. \& Siperstein, M. (1984). Individual patterns of interaction in the mother-child dyad: Implications for parent intervention. Topics in Language Disorders, 4, 50-61. 
Wanska, S.K. \& Bedrosian, J.L. (1985). Conversational structure and topic performance in mother-child

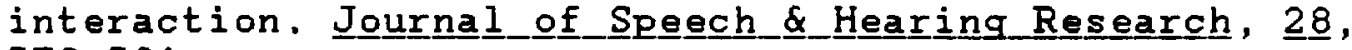
579-584.

Wanska, S.K. \& Bedrosian, J.L. (1986). Topic and communicative intent in mother-child discourse. Journal

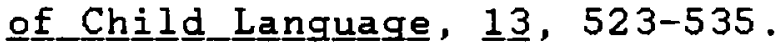

Whitehurst, G.J., Fischel, J.E., Lonigan, C.J., ValdezMenchaca, M.C.. DeBaryshe, B.D. \& Caulfield. (1988). Verbal interaction in families of normal and expressive-language-delayed children. Developmental Psychology, 24, 690-699.

Yoder, P.J. \& Kaiser, A.P. (1989). Alternative explanations for the relationship between maternal verbal interaction style and child language development. Jourrnal of Child Language, $16,141-160$. 
APPENDIX A

DESCRIPTION OF MATERNAL PARAMETERS 


\section{DESCRIPTION OF MATERNAL PARAMETERS}

1) Mothenerese: is a set of characteristic differences in speech directed to toddlers (Chapman, 1981). Changes are made in phonology, syntax, semantics and pragmatics.

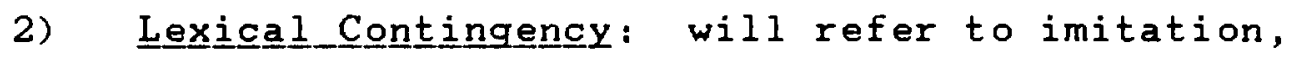
extension and expansion (Moellman-Landa \& Olswang, 1984) and refarence to child's activity. a. Imitation: occurs when the adult repeats the child's utterance, either in its entirety or partially. For example: Child: All gone.

Mother: Yes, all gone.

b. Expansion: refers to the "adult's more mature version of a child's utterance that preserves the word order of the original child utterance" (Owens, 1984, P. 378).

For example: Child: All gone.

Mother: Yes, it's all gone.

c. Extension: refers to the "adult's semantically related comment on (the) topic established by a child" (Owens, 1984, P. 378).

For example: Child: All gone. 
Mother: Yes, it's all gone and now it's empty. d. Reference to child's activity: refers to utterances which relate to the child's on-going activity.

For example: The child is dressing a doll and the mother says, "What a pretty dress!"

4) Praggmatic Function: refers to the intent or purpose of the utterance (Folger \& Chapman, 1978; Dore, 1977). The following pragmatic functions are included:

a. Requests for information: this refers to questions which solicit information from the child.

Internal State: refers to the child's state of being, feelings, opinions or activities (Sachs \& Devin, 1976).

For example: Is Johnny playing?

Clarification: refers to a request for more information to provide the mother with a better understanding of the child's utterances.

For example: The ball is what?

\section{Huh?}

External State: refers to things other than the child and his/her activites (Sachs \& Devin, 1976). For example: Is the ball rolling?

b. Comments: this refers to descriptions and statements of feelings, facts, rules, attitudes, and beliefs (Dore, 1977). 
Positive Comments: statements not refuting or correcting the child's utterances.

Example: You're riding the horsie.

The doll is sick.

Negative Comments: refers to utterances which reject and/or correct the child's utterance (Bondurant, Romeo \& Kretschmer, 1983).

Example: You're not riding the cow! You're riding the horsie.

c. Requests for Actions: will refer to those utterances whose intent is to get the child to do something or to stop doing something. These may be imperatives, statements or questions in syntactic structure.

Examples: Why don't you feed the doll?

Get a black doll.

Will you stop that?

Don't make a mess.

d. Conversational Devices: refers to those devices used to keep a conversation going.

Examples: Oh.

Yes.

Thank you.

e. Bids for Attention: refers to those devices which are used to regulate contact and conversation. This is exemplified whenever the mother tries to get the 
child's attention.

Examples: Lookit!

Hey, John.

f. Responses to Child's Bids for Attention: refers to those responses to devices which are used to regulate contact and conversation. This is exemplified whenever the mother responds to the child's bid for attention.

Examples: Yes?

What do you want?

Hmm?

5) Syntaxㅡ: will refer to sentence organization. The following catagories will be scored:

a. Declaratives: makes a statement.

Example: The ball is red.

b. Negatives: negates a statement.

Example: The ball isn't red.

c. Questions: requests information or action.

Questions are either $W h, Y / N$ or tag in construction.

i) Wh: uses who, what, where, when, why or how to make the inquiry.

Example: What is this?

Who is this?

ii) $Y / N$ : uses interrogative reversal to make the inquiry. Can be answered with Yes or No. 
Example: Is the dollie sick?

Are you being silly?

iii) Tag: is an affirmative statement with a negative question.

Example: She's tired, isn't she?

d. Complex sentences: use two main verbs.

Example: I think that you are silly.

e. Imperatives: refers to a command or an entreaty.

Example: Stop doing that!

Pick up your toys!

f. Fragments versus complete sentences: lacks some component of the Noun + Verb.

Example: Going up. (Lacks the subject.)

g. Mean Length of Utterance (MLU): Utterance boundaries will be defined as "a unit of spoken language preceded and followed by a perceived pause or terminated by some change in inflection (rising or falling intonation)" (Moellman-Landa \& Olswang, 1984, P. 121). MLU will be determined following Brown's rules (Miller, 1981).

6) Topic Managgement: refers to which conversational partner, the mother or the child, initiates and maintains the topic. Topic management will be scored in the following areas:

a. Introduction of new topic - this will be scored whenever the mother refers to a topic which has 
not been previously talked about during the interaction. Thus if some attention was already paid to the topic previously, it will not be scored.

b. Reintroduction of maternal topic - this will be scored whenever the mother initiates a topic which was previously initiated by her and was discussed. At least one other topic will have occurred between the topic's last occurrence and its reintroduction by the mother.

c. Responding to the child's topic - this will be scored whenever the mother maintains the child's choice of topic, following his lead.

d. Reintroduction of child's topic - will be scored whenever the mother reintroduces a topic previously chosen by the child. At least one other topic will have ensued between the topic's introduction and its reintroduction.

e. Maintaining own topic - will be scored whenever the mother continues talking about her own topic. 


\section{APPENDIX B}

HUMAN SUBJECTS RESEARCH REVIEW COMMITTEE APPROVAL 


\section{Portland State University}

\section{MEMORANDIN}

HUMAN SUBJECTS RESEARCH REVIEW COMMITTEE 1987.88

-DATE: 3 May 1988

TO: Rhea Paul, SP

FROM: Robert C. Holloway, Chalrperson

Human Subjects Research Revlew Comittee (HSRRC)

RE: HSRRC APproval

In accordance with your request, the Human Subjects Research Review Committee has reviewed your proposal entitled Late Bloomers?

Communication Skills in Non-Speaker Ioddlers: Follow-up Studv for compliance with DHHS policies and regulations on the protection of human subjects.

The committee is satisfied that your provisions for protecting the rights and welfare of all subjects participating in the research are adequate and therefore the project is approved.

c: Office of Grants and Contracts

RCH:asm 


\section{APPENDIX C}

\section{QUESTIONNAIRE FOR PARENTS OF}

CHILDREN 15-30 MONTHS OLD 
QUESTIONNAIRE FOR PARENTS OF CHILDREN 15-30 MONTHS OLD

What is your child's:

first name ?

date of birth?

Mother's occupation?

Father's occupation?

Mother's phone number?

How many different words can your child say? (It's OK if the words aren't entirely clear, as long as you can understand them.) none

less than five $10-30$

5- 10 $30-50$

If your child says fewer than ten words, please list them here:

Does your child put words together to form short "sentences? Yes No

If yes, please give three examples here:

Would you be interested in participating in later parts of this study? Yes No

Thank you again for your help: 
APPENDIX D

INFORMED CONSENT 


\section{INFORMED CONSENT}

I, , hereby agree to

serve as a subject in the research project on language development in young children conducted by Rhea Paul.

I understand that the study involves seeing my child yearly for speech and language evaluation and videotaping conversations between me and my child. I understand that these tapes will be transcribed for analysis of my child's spoken language patterns.

It has been explained to me that the purpose of the study is to learn whether children who begin talking late are at risk for later learning problems.

I may not receive any direct benefit from participation in this study, but my participation may help to increase knowledge which may benefit others in the future.

Dr. Paul has offered to answer any questions I may have about the study and what is expected of me in the study. I have been assured that all information I give will be kept confidential and that the identity of all subjects will remain anonymous.

I understand that I am free to withdraw from participation in this study at any time without jeopardizing my relationship with Portland State University.

I have read and understand the foregoing information.

Date Signature

If you experience problems that are the result of your participation in this study, please contact the secretary of the Human Subjects Research and Review Committee, Office of Grants and Contracts, 303 Cramer Hall, Portland State University, 464-3417. 
APPENDIX E

VOCABULARY CHECKLIST 


\section{VOCABULARY CHECKLIST}

Please circle each word your child says. Don't include words your child can understand but not say. It's ok to count words that aren't pronounced clearly. If your child speaks a foreign language, please check off English versions of the words he uses.

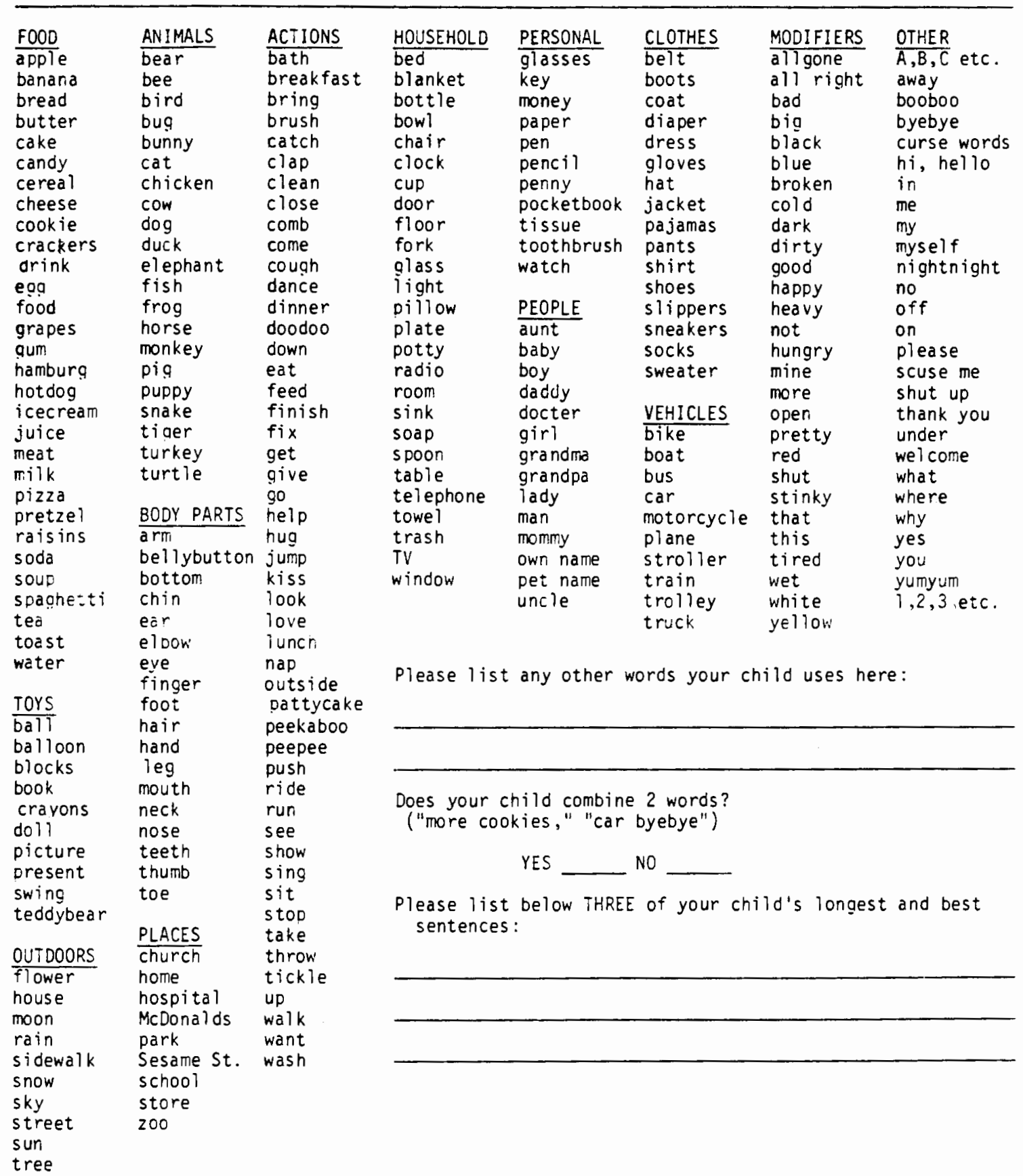


APPENDIX F

DEMOGRAPHIC DATA 
DEMOGRAPHIC DATA

CONTROL GROUP

$\underset{\#}{\text { Subject Sex Age in Months }}$ SES Race

\begin{tabular}{|c|c|c|c|c|}
\hline $\begin{array}{l}12 \\
14 \\
27 \\
32 \\
36 \\
39 \\
40 \\
41 \\
50 \\
55 \\
56 \\
58 \\
59 \\
63 \\
69 \\
72 \\
81 \\
113 \\
126 \\
128 \\
129 \\
130 \\
131 \\
132 \\
133 \\
138 \\
139\end{array}$ & $\begin{array}{l}F \\
M \\
M \\
M \\
F \\
M \\
F \\
M \\
M \\
F \\
F \\
M \\
F \\
M \\
M \\
M \\
F \\
F \\
F \\
M \\
M \\
M \\
M \\
M \\
M \\
M \\
F\end{array}$ & $\begin{array}{l}22 \\
25 \\
22 \\
29 \\
28 \\
22 \\
25 \\
21 \\
24 \\
26 \\
21 \\
34 \\
34 \\
19 \\
16 \\
20 \\
26 \\
26 \\
29 \\
27 \\
33 \\
29 \\
31 \\
20 \\
27 \\
23 \\
29\end{array}$ & $\begin{array}{l}1 \\
1 \\
4 \\
4 \\
1 \\
2 \\
4 \\
2 \\
1 \\
3 \\
1 \\
1 \\
1 \\
3 \\
3 \\
4 \\
5 \\
3 \\
1 \\
2 \\
5 \\
3 \\
2 \\
1 \\
4 \\
4 \\
2\end{array}$ & $\begin{array}{l}\text { White } \\
\text { White } \\
\text { White } \\
\text { Black } \\
\text { White } \\
\text { White } \\
\text { White } \\
\text { White } \\
\text { White } \\
\text { White } \\
\text { White } \\
\text { White } \\
\text { White } \\
\text { White } \\
\text { Mixed } \\
\text { White } \\
\text { White } \\
\text { White } \\
\text { White } \\
\text { White } \\
\text { White } \\
\text { White } \\
\text { White } \\
\text { Mixed } \\
\text { White } \\
\text { White } \\
\text { White }\end{array}$ \\
\hline
\end{tabular}


DEMOGRAPHIC DATA

EXPERIMENTAL GROUP

$\underset{\#}{\text { Subject Sex Age in Months RES Race }}$

\begin{tabular}{|c|c|c|c|c|}
\hline 7 & M & 23 & 2 & White \\
\hline 19 & $\mathrm{~F}$ & 32 & 4 & White \\
\hline 26 & M & 31 & 3 & Black \\
\hline 29 & F & 26 & 5 & White \\
\hline 51 & F & 20 & 4 & White \\
\hline 57 & $F$ & 20 & 4 & White \\
\hline 84 & M & 20 & 4 & White \\
\hline 85 & M & 28 & 3 & White \\
\hline 86 & M & 20 & 2 & White \\
\hline 89 & $F$ & 24 & 4 & White \\
\hline 90 & M & 28 & 3 & White \\
\hline 91 & M & 27. & 3 & White \\
\hline 92 & M & 33 & 3 & White \\
\hline 93 & M & 24 & 3 & White \\
\hline 94 & M & 31 & 3 & White \\
\hline 97 & $M$ & 22 & 3 & White \\
\hline 98 & M & 19 & 2 & White \\
\hline 100 & $M$ & 29 & 2 & White \\
\hline 101 & $F$ & 25 & 4 & White \\
\hline 103 & M & 25 & 2 & White \\
\hline 107 & M & 22 & 2 & White \\
\hline 109 & M & 21 & 3 & White \\
\hline 111 & $\mathrm{~F}$ & 25 & 3 & White \\
\hline 114 & M & 24 & 2 & Mixed \\
\hline 119 & M & 26 & 2 & White \\
\hline 122 & F & 27 & 2 & Black \\
\hline 142 & $F$ & 22 & 1 & White \\
\hline 145 & $F$ & 29 & 4 & White \\
\hline
\end{tabular}




\section{APPENDIX G}

TRANSCRIPTION FORM 


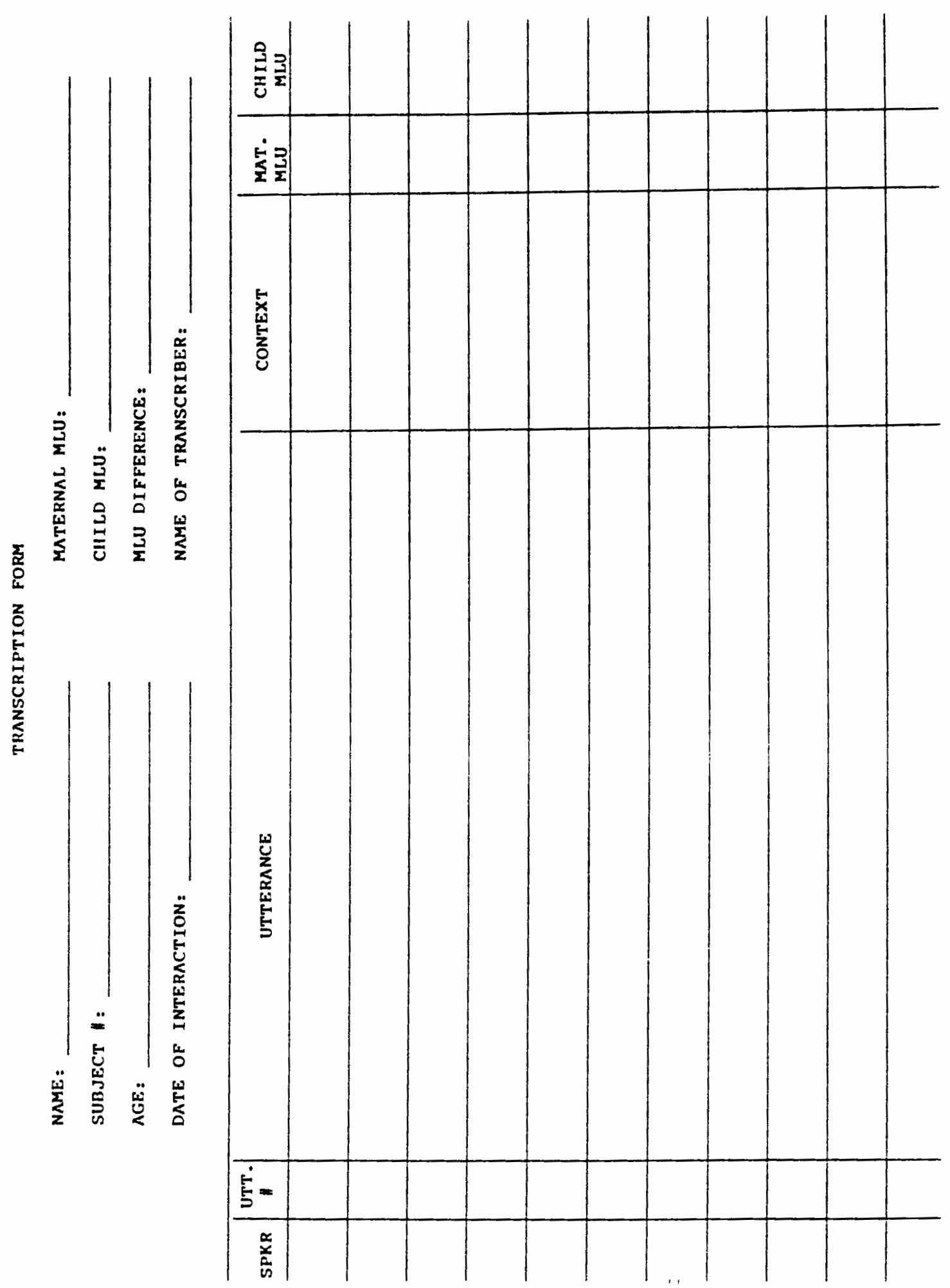


APPENDIX $\mathrm{H}$

SCORING FORMS 
Subject

MOTHER'S SYNTAX

Percent

Occurrence

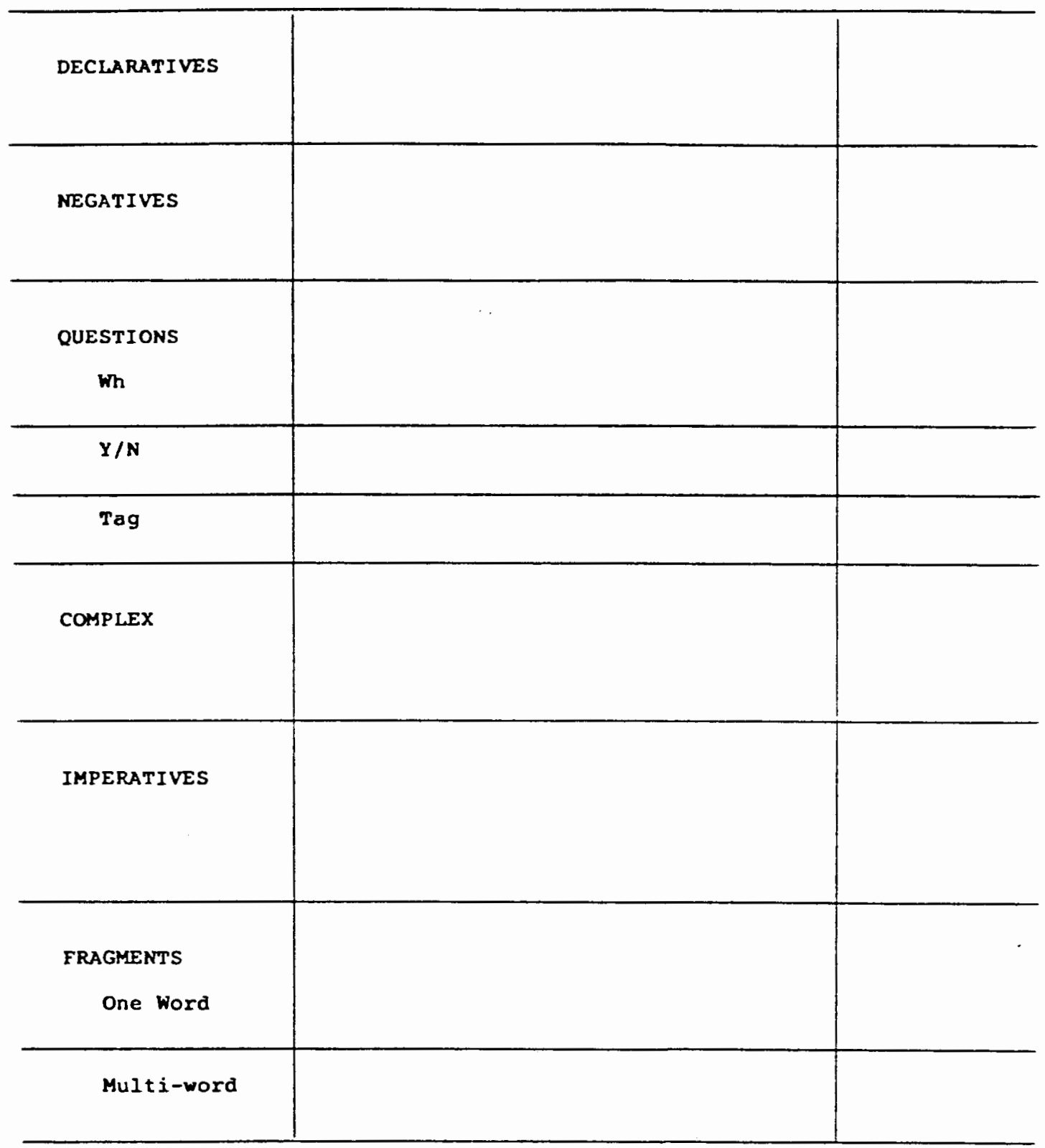

MATERNAL MLU:

CHILD MLU:

DIFFERENCE : 
subject

MOTHER'S IEXICAL CONTINGENCY

Percent

Occurrence

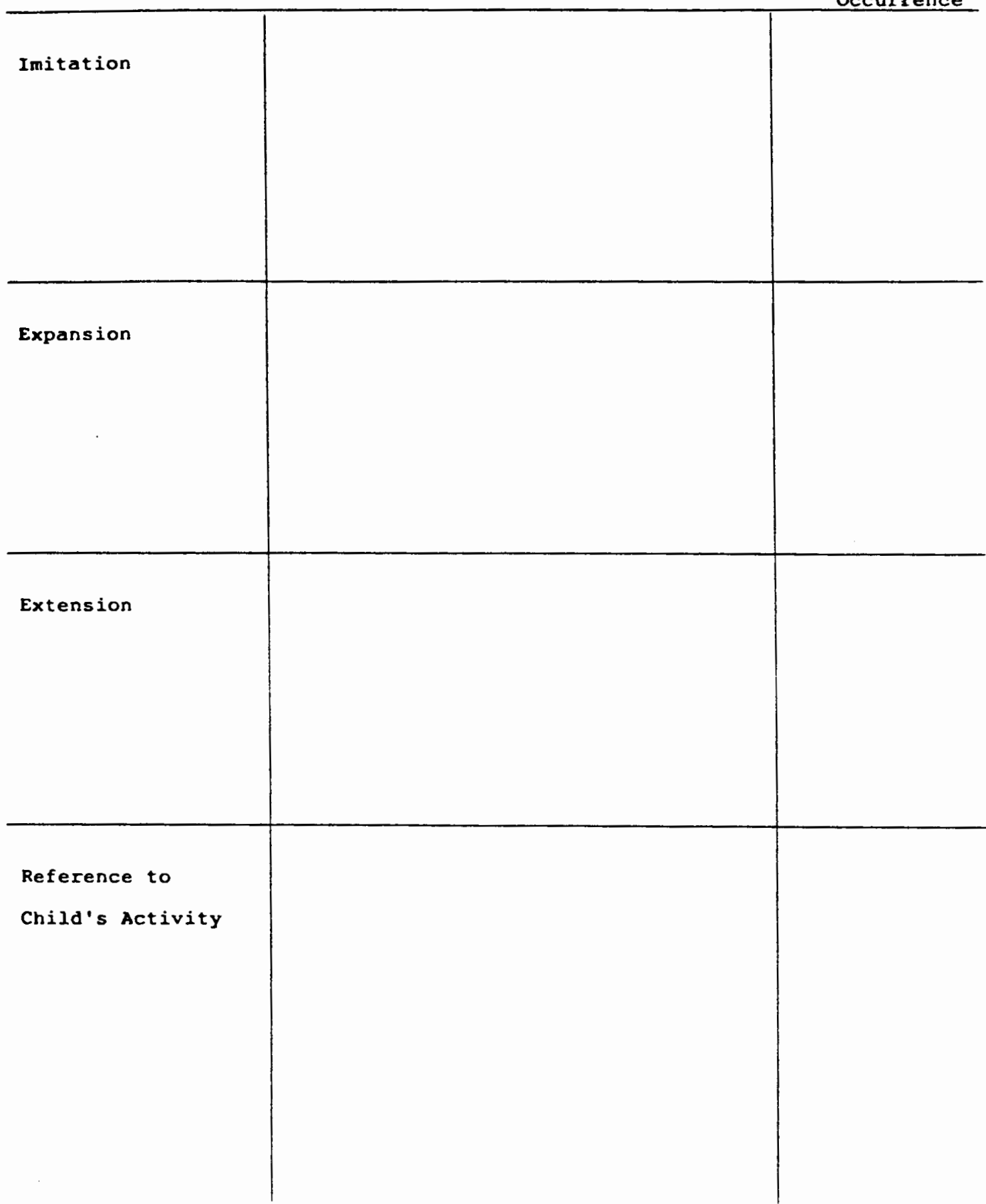


Subject

MOTHER'S PRAGMATIC FUNCTIONS

Percent

Occurrence

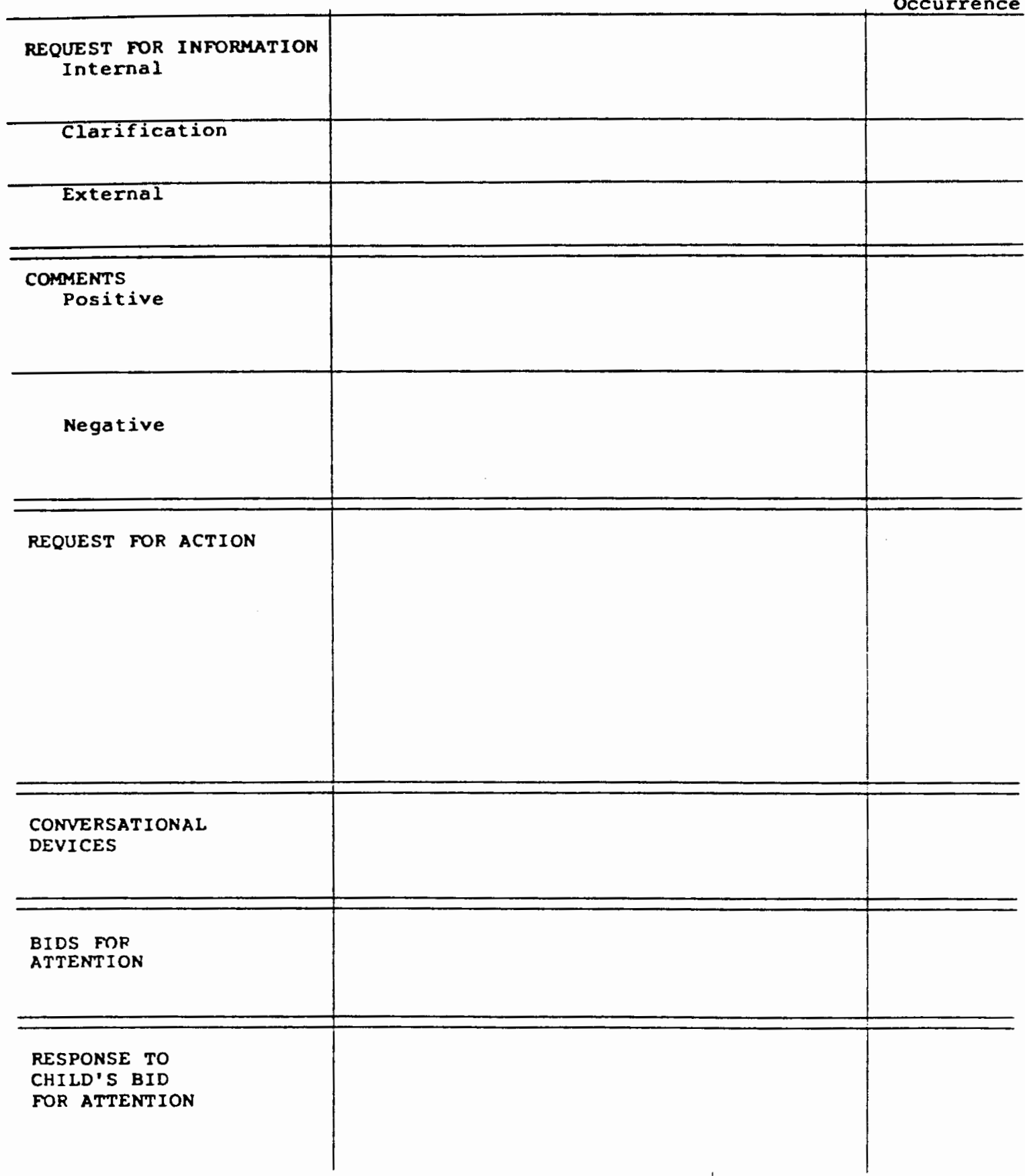


Subject

MOTHER'S TOPIC MANAGEMENT

Percent

Occurrence

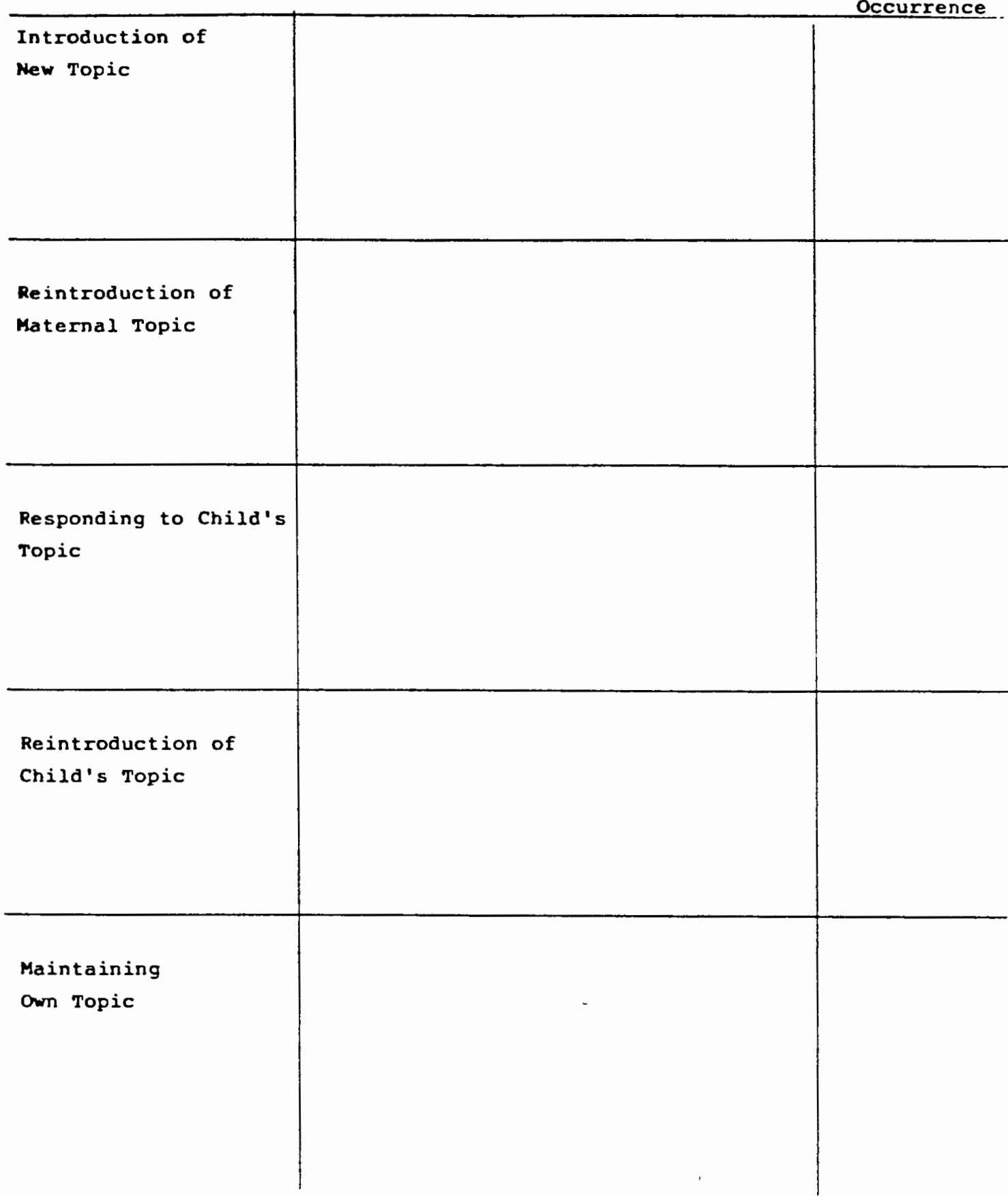

